\title{
Myeloid-Derived Suppressor Cells in Bacterial Infections
}

\author{
Michael Ost ${ }^{1}$, Anurag Singh ${ }^{1}$, Andreas Peschel ${ }^{2}$, Roman Mehling ${ }^{1}$, Nikolaus Rieber ${ }^{1,3}$ and \\ Dominik Hartl ${ }^{1 *}$
}

${ }^{1}$ Children's Hospital, University of Tübingen, Tübingen, Germany, ${ }^{2}$ Infection Biology Department, Interfaculty Institute of Microbiology and Infection Medicine, University of Tübingen, Tübingen, Germany, ${ }^{3}$ Department of Pediatrics, Kinderklinik München Schwabing, Klinikum Schwabing, StKM GmbH und Klinikum rechts der Isar, Technische Universität München, Munich, Germany

Myeloid-derived suppressor cells (MDSCs) comprise monocytic and granulocytic innate immune cells with the capability of suppressing T- and NK-cell responses. While the role of MDSCs has been studied in depth in malignant diseases, the understanding of their regulation and function in infectious disease conditions has just begun to evolve. Here we summarize and discuss the current view how MDSCs participate in bacterial infections and how this knowledge could be exploited for potential future therapeutics.

Keywords: MDSC, myeloid-derived suppressor cells, bacteria, infection, immune suppression, sepsis

\section{INTRODUCTION}

\section{OPEN ACCESS}

Edited by:

Ashok K. Chopra,

University of Texas Medical Branch,

USA

Reviewed by:

Frank C. Gibson III,

Boston University Medical Center,

USA

Kiyoshi Itagaki,

Beth Israel Deaconess Medical Center/Harvard Medical School, USA

Irina Pinchuk,

University of Texas Medical Branch,

USA

${ }^{*}$ Correspondence:

Dominik Hart

dominik.hart/@med.uni-tuebingen.de

Received: 25 December 2015 Accepted: 15 March 2016 Published: 31 March 2016

Citation:

Ost M, Singh A, Peschel A, Mehling R, Rieber N and Hartl D (2016)

Myeloid-Derived Suppressor Cells in

Bacterial Infections.

Front. Cell. Infect. Microbiol. 6:37.

doi: 10.3389/fcimb.2016.00037
Bacterial infections represent one of the major threats for the human immune system. Particularly, in vulnerable populations, such as elderly people or patients after surgery, they can lead to sepsis or death (Martin et al., 2003). A functional immune response is a key factor to control the outcome of bacterial infections. Therefore, the human immune system has evolved several effector mechanisms to combat bacteria, involving the innate and the adaptive arm of the immune system. While phagocytic cells, mainly neutrophils and macrophages, are traditionally regarded as key players in host-bacteria interactions (Kruger et al., 2015), research focus has shifted toward a heterogeneous group of myeloid cells, which suppress immune responses, termed myeloid-derived suppressor cells (MDSCs) (Gabrilovich et al., 2007). First described in cancer (Young et al., 1987; Gabrilovich and Nagaraj, 2009; Waldron et al., 2013), subsequent studies highlighted the potential role of MDSCs in auto-immune and infectious diseases (Haile et al., 2008; Tacke et al., 2012). Notably, MDSC induction and immunosuppressive activity has been shown in infections with hepatitis $\mathrm{C}$ virus (Tacke et al., 2012; Goh et al., 2016). Elevated MDSCs were also found in HIV patients (Qin et al., 2013; Tumino et al., 2015), in other viral infections as well as in fungal and parasitic infections (Van Ginderachter et al., 2010; Goh et al., 2013; Rieber et al., 2015). Distinct MDSC subphenotypes have been described depending on the infectious agent and the stage of disease (Norris et al., 2013; Janols et al., 2014). Therapeutically, several approaches on how to interfere with or target MDSCs have been discovered and are subject to preclinical and clinical studies in cancer (Gabrilovich et al., 2001; Ko et al., 2009; Nagaraj et al., 2010b). In this review, we describe the state of research on MDSCs in bacterial infections. Furthermore, we focus on the molecular mechanisms that mediate pathogen recognition and MDSC activation in bacterial infections.

\section{MDSCs}

\section{MDSC Characterization}

MDSCs comprise a heterogeneous group of immature myeloid cells that suppress effector immune cells, mainly T-cells and natural killer (NK) cells. Two major MDSC subsets have been 
described that differ substantially by morphology as well as immunosuppressive mechanisms: (i) granulocytic/neutrophilic MDSCs (PMN-MDSCs) and (ii) monocytic MDSCs (MMDSCs) (Youn et al., 2008). In mice, PMN-MDSCs are $\mathrm{CD}_{11 b^{+}} \mathrm{Ly}_{6 \mathrm{G}}{ }^{+} \mathrm{Ly}_{6 \mathrm{C}}{ }^{\text {low }}$, whereas M-MDSCs are CD11b ${ }^{+}$Ly6G $^{-}$Ly6C $C^{\text {high }}$ (Movahedi et al., 2008; Youn et al., 2008). In humans, MDSCs have been described as

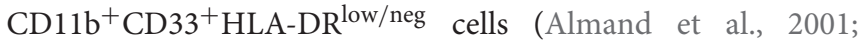
Ochoa et al., 2007). The subset of PMN-MDSCs is CD14and expresses $\mathrm{CD}_{6} 6 \mathrm{~b}^{+}$and $\mathrm{CD}^{+} 5^{+}$, while M-MDSCs are CD14 $^{+}$(Zea et al., 2005; Filipazzi et al., 2007; Condamine et al., 2015). Divergent gene expression profiles have been proposed to allow discrimination between MDSCs and other granulocytes/monocytes (Gabrilovich et al., 2012; Condamine et al., 2015). However, the phenotypic characterization is not sufficient to identify MDSCs and an additional proof of the immunosuppressive function is necessary. While PMN-MDSCs have been described as the predominant subset in many cancers, M-MDSCs are involved in melanoma (Filipazzi et al., 2007; Mandruzzato et al., 2009) and chronic infections (Cai et al., 2013; Nagaraj et al., 2013). M-MDSCs are also capable of differentiating into PMN-MDSCs (Youn et al., 2013).

\section{MDSC Expansion and Activation}

Immature myeloid cells can be found in healthy individuals at low amounts in peripheral blood (Almand et al., 2001), which increase upon cancer, inflammation and infection. MDSC expansion and activation mechanisms depend on the MDSC phenotype and the species studied (Serafini, 2013; Condamine et al., 2015; Figure 1). MDSC expansion is mainly driven by STAT3, a transcription factor activated by GM-CSF, GCSF, VEGF as well as IL-6 (Gabrilovich et al., 1998; Serafini et al., 2004; Song et al., 2005; Sawanobori et al., 2008), that influences cell proliferation and differentiation (Yu et al., 2009). Activated STAT3 also induces expression of S100A8 and A9 (Foell et al., 2007), which block differentiation of immature myeloid cells and lead to expansion of MDSCs (Cheng et al., 2008). In vivo inhibition of STAT3 via receptor tyrosine kinase inhibitor Sunitinib resulted in a lower amount of MDSCs (Xin et al., 2009). Other related transcription factors of the STAT family, particularly STAT1 and STAT6, also play a role in MDSC activation and function (Movahedi et al., 2008; Munera et al., 2010). STAT1 can be triggered by IFN- $\gamma$, whereas STAT6 response is initiated by IL-4 and IL-13 (Rutschman et al., 2001). Downstream, MDSC activation is primarily mediated by $N F \kappa B$, which is triggered by pro-inflammatory mediators such as IL- $1 \beta$ and TNF- $\alpha$ (Tu et al., 2008; Hu et al., 2014) or toll-like receptor signaling via MyD88 (Delano et al., 2007). Furthermore, NFкB is involved in the ER stress response that is active in MDSCs (Condamine et al., 2014).

\section{Immunosuppressive Mechanisms of MDSCs}

MDSCs are employed with several mechanisms to suppress immune cells. MDSCs express arginase-1, an enzyme that converts L-arginine into urea and L-ornithine (Wu and Morris, 1998), which is required for functional T-cell responses (Zea et al., 2004). MDSCs are equipped with another enzyme targeting L-arginine, the inducible NO-synthase (iNOS) that catalyzes the production of citrulline and NO from L-arginine ( $\mathrm{Wu}$ and Morris, 1998), thereby amplifying L-arginine deprivation. Additionally, NO disrupts signaling pathways downstream of the IL-2 receptor (Mazzoni et al., 2002), promoting T-cell apoptosis (Garban and Bonavida, 2001) and formation of peroxynitrite. This represents one of the most powerful oxidants that is capable of altering the TCR and CD8-molecules via nitration. Thereby these receptors no longer react to antigen-specific stimulation (Nagaraj et al., 2007). Chemokines, such as CCL2, can be nitrated and amino acids as cysteine can be oxidated by peroxynitrite, which impairs T-cell response (Molon et al., 2011). MDSCs also interfere directly with cysteine metabolism by importing cysteine, but lack of an export mechanism contrary to other myeloid cells. As consequence, T-cells run short of cysteine and are left with impaired activation and function (Srivastava et al., 2010). Beyond NO, MDSCs produce another source of oxidants, reactive oxygen species (ROS) (Youn et al., 2008), which disrupt the T-cell function by modifying its TCR- $\zeta$-chain (Nagaraj et al., 2010a). Importantly, MDSC subsets differ in their immunosuppressive mechanisms (Movahedi et al., 2008; Youn et al., 2008). While M-MDSCs and PMN-MDSCs express comparable amounts of arginase-1, substantial differences are found for NO and ROS. M-MDSCs mainly generate NO (Movahedi et al., 2008), whereas PMN-MDSCs produce higher levels of ROS (Youn et al., 2008). Beyond suppressing T-cells, MDSCs also interact in a more dynamic way with T-cells by acting as antigen presenting cells for CD8 ${ }^{+}$T-cells (Watanabe et al., 2008). Additionally, MDSC activity is enhanced by activated T-cells (Nagaraj et al., 2012), while T-cells can also induce MDSC apoptosis by engaging the Fas/FasL axis (Sinha et al., 2011). Besides dampening T-cells, MDSCs are also known to influence the activity and function of other myeloid cells (Ostrand-Rosenberg et al., 2012). By releasing IL-10, MDSCs suppress IL-12 production by macrophages and DCs, rendering them less capable of activating T-cells (Sinha et al., 2007). Another subset of cells dampening T-cell responses are regulatory $\mathrm{T}$-cells $\left(\mathrm{T}^{\mathrm{reg}}\right)$, which exhibit cross-talk with MDSCs (Hoechst et al., 2008). MDSCs have been shown to promote the expansion of $\mathrm{T}^{\text {regs }}$ (Hoechst et al., 2008; Serafini et al., 2008), while some other studies demonstrate more complex scenarios of interaction (Dugast et al., 2008; Movahedi et al., 2008).

\section{MDSCs AND BACTERIAL INFECTIONS}

\section{TLR Ligands}

Bacterial pathogens are recognized by immune cells through defined pattern recognition receptors (PRRs). These PRRs are capable of identifying so called pathogen-associated molecular patterns (PAMPs) (Janeway and Medzhitov, 2002), typically microbial cell envelope components, nucleic acids, or polysaccharides (Akira et al., 2006). Toll-like receptors (TLRs) represent the prototypic PRRs sensing bacterial infections. TLRs on the cell surface mainly recognize bacterial molecular patterns, while viral pathogens are detected by intracellular TLRs (Kawai and Akira, 2010). TLR2 is a key TLR in bacterial sensing that 


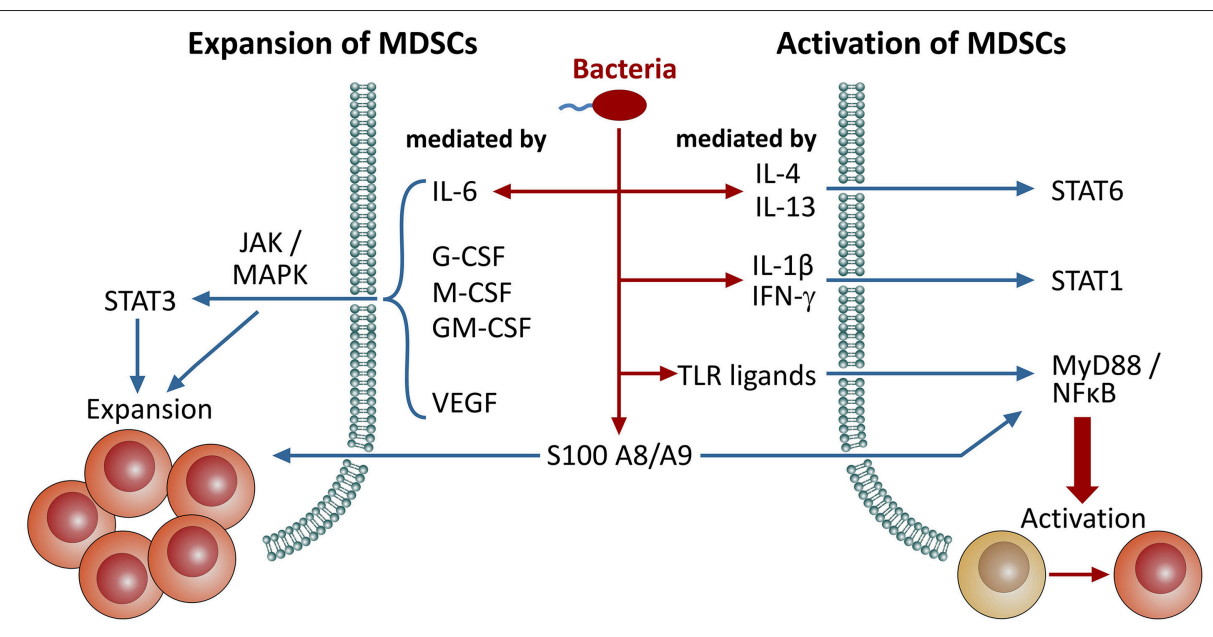

FIGURE 1 | Signaling pathways involved in the expansion and activation of MDSCs. Induction/expansion and activation of MDSCs can be triggered through distinct pathways. Here, we provide an overview on different signaling molecules and pathways involved in these events. Bacterial infections either directly promote MDSC activation through microbial patterns (PAMPS), TLR ligation and NF $\kappa$ B-dependent pathways or indirectly through pro-inflammatory mediators, such as several interleukins and IFN- $\gamma$, that are secreted upon infection. Furthermore, S100 proteins are also involved in both of these processes.

forms heterodimers with TLR1 and TLR6 (Akira et al., 2006). The TLR1-TLR2 heterodimer binds with lipopeptides of Gramnegative bacteria (Wyllie et al., 2000), whereas lipoproteins of Gram-positive bacteria are recognized by the TLR2-TLR6 heterodimer (Ozinsky et al., 2000). TLR4 responds to bacterial lipopolysaccharides (LPS) (Poltorak et al., 1998), which is localized in the cell membrane of Gram-negative bacteria. Flagellin, a prominent component of bacterial flagella known to stimulate host defense, is detected by TLR5 (Hayashi et al., 2001) and bacterial DNA motifs are sensed by TLR9 (Hemmi et al., 2000). Notably, TLRs can also be activated by molecular patterns that are released from stressed or damaged cells, so called damage- or danger-associated molecular patterns (DAMPs) (Asea et al., 2002). The synthetic lipopeptide and TLR2/6 agonist Pam2CSK4 has been shown to induce MDSC expansion and prolonged MDSC survival (Maruyama et al., 2015). Likewise for TLR4, LPS triggered MDSC expansion and activation using the MyD88-dependent signaling pathway in several in vitro as well as in vivo studies (Delano et al., 2007; Bunt et al., 2009). While MDSC generation was partly independent of MyD88, MyD88 activity was essential for their immunosuppressive functionality (Hong et al., 2013). We reported previously that the TLR5 ligand flagellin induced MDSC expansion (Rieber et al., 2013). Thus, several TLRs that detect bacterial PAMPs are reported to enhance MDSC frequency and activity. However, some TLR agonists are also used in anti-tumor therapy and show adverse effects on MDSC expansion and activity (Aranda et al., 2014). Hence, studies reported that Poly (I:C), a TLR3 agonist, reduced MDSC frequency and inhibited immunosuppressive effects (Zoglmeier et al., 2011). Stimulation of TLR9 with CpG oligonucleotides induced differentiation of M-MDSCs and led to a loss of their immunosuppressive function (Zoglmeier et al., 2011; Shirota et al., 2012). A combination of TLR7-9 ligands enhanced anti-tumor responses by NK cells and cytotoxic T-cells and reduced MDSC frequency (Zhao et al., 2014).

\section{Bacteria}

Several Gram-positive and -negative bacteria have been shown to induce or modulate MDSCs in vitro and in vivo. These studies are summarized and discussed in the section below (Table 1).

Staphylococcus aureus is a Gram-positive bacterium and a major bacterial pathogen in humans that mainly colonizes the nasal cavity of $20-30 \%$ of the population and poses a risk of invasive infections for these carriers (Foster, 2004; Weidenmaier et al., 2012). Antibiotic-resistant strains, particularly methicillinresistant S. aureus (MRSA) represent a major problem all over the world (Smith et al., 1999; Saeed et al., 2014). Lipoproteins anchored to the cytoplasmic membrane are known to act as TLR2-ligands (Nguyen et al., 2015) and it is already known that $S$. aureus is able to evade immune responses by impairing T-cell function (Fedtke et al., 2004; Schreiner et al., 2013). The expansion of both MDSC subsets and immunosuppressive activity was shown in S. aureus skin infection models (Skabytska et al., 2014). MDSC-mediated immune suppression was mainly dependent on iNOS and, to a lesser extent, on arginase-1. S. aureus causes infections and forms biofilms in orthopedic implants where an impaired immune response has been reported (Thurlow et al., 2011). In these biofilms, elevated MDSC frequencies have been found with enhanced expression of arginase-1, iNOS and IL-10 (Heim et al., 2014). Consistent with these findings, depletion of MDSCs led to improved bacterial clearance (Heim et al., 2014), while MDSC activity increased disease severity in this biofilm model (Heim et al., 2015b). In line with this concept, it was shown that adoptive transfer of MDSCs in S. aureus infected mice led to an aggravation of disease (Tebartz et al., 2015). Taken together, the studies on MDSCs in S. aureus infections suggest that MDSCs play a rather harmful role in S. aureus infected hosts.

Tuberculosis due to infection with Mycobacterium tuberculosis is one of the most prominent infectious diseases 
TABLE 1 | Bacterial MDSC induction and impact on disease outcome.

\begin{tabular}{|c|c|c|c|c|}
\hline Pathogen & $\begin{array}{l}\text { Expanding MDSC } \\
\text { subsets }\end{array}$ & Study type & Outcome & References \\
\hline Staphylococcus aureus & PMN- and M-MDSCs & $\begin{array}{l}\text { In vitro, in vivo (mouse } \\
\text { and human) }\end{array}$ & Aggravation of infection & $\begin{array}{l}\text { Thurlow et al., 2011; Heim et al., 2014, 2015a,b; } \\
\text { Skabytska et al., 2014; Tebartz et al., } 2015\end{array}$ \\
\hline Mycobacterium tuberculosis & PMN- and M-MDSCs & $\begin{array}{l}\text { In vivo (mouse and } \\
\text { human) }\end{array}$ & Aggravation of infection & $\begin{array}{l}\text { Obregon-Henao et al., 2013; du Plessis et al., } \\
\text { 2013; Knaul et al., 2014; Tsiganov et al., 2014; } \\
\text { Yang et al., 2014; El Daker et al., } 2015\end{array}$ \\
\hline Pseudomonas aeruginosa & PMN-MDSCs & In vitro, in vivo (human) & $\begin{array}{l}\text { Host protection (associated } \\
\text { with better lung function) }\end{array}$ & Rieber et al., 2013 \\
\hline Klebsiella pneumoniae & PMN-MDSCs & In vivo (mouse) & Host protection & Cai et al., 2009; Poe et al., 2013 \\
\hline Porphyromonas gingivalis & Not mentioned & In vivo (mouse) & Not mentioned & Ezernitchi et al., 2006 \\
\hline Polymicrobial sepsis & PMN- and M-MDSCs & $\begin{array}{l}\text { In vivo (mouse and } \\
\text { human) }\end{array}$ & Host protection & $\begin{array}{l}\text { Delano et al., 2007; Sander et al., 2010; } \\
\text { Brudecki et al., 2012; Darcy et al., 2014; Janols } \\
\text { et al., 2014; McClure et al., } 2014\end{array}$ \\
\hline
\end{tabular}

worldwide with an estimated 9 million reported cases annually and reports suggest that mortality rates are much higher than those of other bacterial infections (Jassal and Bishai, 2010). In mice, heat-killed M. tuberculosis is able to induce MDSCs, which produce NO and superoxide anion (Dietlin et al., 2007). Likewise, patients with active tuberculosis as well as patients that had been recently exposed with $M$. tuberculosis exhibited expanded MDSC frequencies in their peripheral blood and bronchoalveolar lavage samples (du Plessis et al., 2013; Yang et al., 2014; El Daker et al., 2015). In vivo studies further demonstrated that MDSCs accumulated in lungs of infected mice where they phagocytized but did not kill the mycobacteria, thereby providing a shelter for intracellular bacteria survival (Knaul et al., 2014). Depletion of MDSCs led to an increase of Tcell frequencies, reduced bacterial burden and improved disease pathology (Knaul et al., 2014), while accumulation of MDSCs was linked with progress and severity of tuberculosis (Tsiganov et al., 2014). However, in a different study phenotypical MDSClike cells were induced by $M$. tuberculosis but failed to inhibit $\mathrm{T}$-cell proliferation. These cells rather promoted Th17 responses (Obregon-Henao et al., 2013), which is in line with previous reports on MDSC-Th17 interactions (Yi et al., 2012; Zhang et al., 2015). Attenuated Mycobacterium bovis, which is also partly used for vaccination against TB, leads to MDSC expansion in a MyD88-dependent manner (Martino et al., 2010). In a similar setting, two subsets of MDSC-like cells were generated recently. M-MDSCs acted as expected, however phenotypical copies of PMN-MDSCs lacked immunosuppressive activity, and rather enhanced the proliferation of $\mathrm{CD}^{+}$and $\mathrm{CD}^{+}{ }^{+}$-cells (Zhan et al., 2015).

Pseudomonas aeruginosa, a flagellated, partly opportunistic and gram-negative bacterium is mainly recognized by the immune system through flagellin/TLR5 signaling (Zhang et al., 2005) and other sensors such as NLRC4 (Franchi et al., 2007). Infections with $P$. aeruginosa are known to affect especially vulnerable patients in a hospital-acquired manner, most frequently ventilated patients in intensive care units, patients with severe burns, cystic fibrosis (CF) patients and chronic obstructive pulmonary disease (COPD) patients.
Bacterial clearance by the immune system of these vulnerable patients is often not successful (Cohen and Prince, 2012). We demonstrated previously that CF patients with chronic $P$. aeruginosa infections featured a higher MDSC frequency in their peripheral blood compared to CF patients without $P$. aeruginosa infections or healthy control subjects (Rieber et al., 2013). In $P$. aeruginosa-infected patients, the percentages of MDSCs correlated with pulmonary function (Rieber et al., 2013). This suggests that MDSC activity induced by $P$. aeruginosa prevents excessive inflammation and leads to improved lung function. As the MDSC expansion was dependent on flagellin as TLR5 ligand, further flagellated bacteria such as Helicobacter pylori or flagellated Escherichia coli strains may also induce MDSC accumulation in the same manner. An increase in MDSC frequency in $H$. pylori infected mice and humans has already been reported (Zhuang et al., 2015). Since there were no studies done using flagellin-deficient $H$. pylori, the potential role of flagellin in this MDSC expansion setting remains elusive.

Klebsiella pneumoniae is another cause of severe pneumonia, mostly acquired in hospitals (Jones, 2010). It is known to activate TLR2 and TLR4 signaling during the infection (Wieland et al., 2011). In mice, infection with $K$. pneumoniae promoted MDSC expansion and thus increased levels of IL-10 (Poe et al., 2013). IL-10 deficient mice were able to clear the infection, but had persistent lung inflammation and enhanced morbidity after infection (Poe et al., 2013). Consequently, IL-10 dependent MDSC activities seem to play a key role in $K$. pneumoniae infection recovery. $K$. pneumoniae infected mice further showed decreased bacterial clearance as well as reduced survival when MyD88 was knocked out (Cai et al., 2009). Contrary to the latter studies, another study found no evidence for MDSC expansion in peripheral blood of pneumonia patients compared to healthy controls (Zhang et al., 2013). However, pneumonia patients included patients with RSV and Rhinovirus infections, so no clear conclusions for bacterial lung infections can be drawn from this study.

Sepsis is defined as a bloodstream infection with a systemic inflammatory response-syndrome (Levy et al., 2003). The most 
common bacteria in bloodstream infections are S. aureus, E. coli, coagulase-negative Staphylococci and K. pneumonia (Weinstein et al., 1997). MDSC expansion and activity during sepsis has been reported in several studies. In a model of polymicrobial sepsis, a MyD88-dependent MDSC expansion was immunosuppressive mainly against $\mathrm{CD}^{+}{ }^{+}$T-cells (Delano et al., 2007). In a similar model the transfer of MDSCs 10 days after induction also inhibited T-cell proliferation and improved the survival rate of septic mice (Derive et al., 2012). Though 3-day-old MDSCs were still able to suppress T-cell proliferation, they expressed less immunosuppressive enzymes after LPS-stimulation and did not improve survival (Derive et al., 2012). The beneficial role of MDSCs in sepsis was supported by another study, which showed that hepatic acute phase proteins were essential for MDSC induction in polymicrobial sepsis and MDSCs prevented sepsisassociated mortality (Sander et al., 2010). In line with murine studies, MDSC expansion and immunosuppressive activity with enhanced expression of arginase was also found in patients with sepsis (Darcy et al., 2014). The induction of MDSCs in sepsis has been linked to specific microRNA signatures (McClure et al., 2014). While PMN-MDSCs were primarily found in sepsis patients with Gram-positive pathogens, M-MDSCs expanded regardless of the Gram staining in all sepsis patients (Janols et al., 2014). Thus, in contrast to the findings in the S. aureus orthopedic implant infection model where MDSCs were harmful, in sepsis MDSCs seem to act in favor of the host. The underlying mechanism for this discrepancy remains to be dissected in future studies, but could be due to (i) the infected compartment (systemic/sepsis vs. localized/compartmentalized) and/or (ii) the respective bacterial pathogen(s).

The Gram-negative Porphyromonas gingivalis is an anaerobic bacterium that is mainly found in the oral cavity where it causes periodontal disease. Mice infected with this bacterium showed an accumulation of MDSCs in their spleen and elevated MDSC frequency in the peripheral blood (Ezernitchi et al., 2006). In mice with chronic Porphyromonas infection, T-cell function was impaired by modulation of the TCR- $\zeta$-chain (Ezernitchi et al., 2006).

\section{Infection-Associated Mediators}

Bacterial infections induce the production of a plethora of proinflammatory cytokines and chemokines. Many of them have also been linked to MDSC expansion and activation in addition to their boost of immune responses against bacteria. Hereby, Interleukins are of great importance, mainly e.g., IL-1 $\beta$, IL4 and IL-6. IL-1 $\beta$ is known to promote MDSC accumulation and suppress T-cell responses (Song et al., 2005). Consistently, blocking IL-1 receptor signaling inhibits MDSC function (Tu et al., 2008). An explanation could be that IL- $1 \beta$ is known to enhance NO production by triggering iNOS expression (Kanno et al., 1994; Kwon et al., 1995), which has been reported to mediate immunosuppression by MDSCs. Similarly, IL-4 and IL13 trigger arginase-1 expression (Rutschman et al., 2001). IL-4 is mainly produced by activated Th2 cells during inflammation (Bronte et al., 2003) and the IL-4 receptor IL-4R $\alpha$ was found to be upregulated on MDSCs (Mandruzzato et al., 2009). Blockade of IL4R $\alpha$ has been reported to induce MDSC apoptosis (Roth et al.,
2012). Furthermore, IL-6 not only induces MDSC expansion (Garg and Spector, 2014), but also stimulates the production of ROS as well as arginase-1 (Chen et al., 2014). Blocking IL-6 led to reduced STAT3 signaling (Wu et al., 2012). In addition to the aforementioned cytokines, TNF- $\alpha$ has also been reported to promote both MDSC expansion and survival (Zhao et al., 2012). Signaling via TNFR-2 leads to NF $\kappa$ B activity, and thereby amplifies immunosuppressive mechanisms of MDSCs (Hu et al., 2014). MDSC expansion is enhanced by inhibiting myeloid cell differentiation, an effect mediated e.g., by S100A8 and S100A9 in a STAT3-dependent manner (Cheng et al., 2008). These S100 proteins were also found to be secreted by MDSCs (SadeFeldman et al., 2013) generating an autocrine feedback loop (Sinha et al., 2008). Notably, S100A8 and S100A9 not only lead to inhibition of myeloid differentiation, but also attract MDSCs to sites of inflammation via NF $\kappa$ B (Sinha et al., 2008). Generated peptide-FC fusion bodies, so called peptibodies, target S100A8 and S100A9 and were able to deplete MDSCs in vitro as well as in vivo (Qin et al., 2014).

\section{CONCLUSIONS}

While cancer-associated MDSCs are traditionally in the focus of research, attention has recently shifted toward the potential role of MDSCs in bacterial infections. MDSC expansion can be triggered through PAMPs from Gram-positive and Gramnegative bacteria (Delano et al., 2007; Maruyama et al., 2015). It has been further proposed that PMN-MDSCs mainly expand in infections caused by Gram-positive bacteria, while M-MDSCs were induced regardless of the Gram staining (Janols et al., 2014). Yet, some principles of TLR-induced MDSC generation remain unclear. While downstream signaling of TLR4 and TLR9 both merge on the MyD88-dependent pathway, TLR4 was found to mediate MDSC expansion and activation, while TLR9 led to reduced MDSC frequencies (Delano et al., 2007; Zoglmeier et al., 2011). Particularly, S. aureus and M. tuberculosis have been shown to potently induce MDSC expansion and MDSCs aggravated disease severity in vivo (Tsiganov et al., 2014; Tebartz et al., 2015). However, in other infectious disease conditions, MDSCs were associated with an improved outcome, such as $P$. aeruginosa infections in CF patients (Rieber et al., 2013) or in polymicrobial sepsis (Sander et al., 2010). The future challenge remains how to translate these findings into therapeutic approaches. A potential therapeutic strategy is to target/deplete MDSCs in settings where they seem to do more harm than good (S. aureus orthopedic implant infections and M. tuberculosis infections). Pharmacologically, the tyrosine-kinase inhibitors Sunitinib and Sorafenib were shown to interfere with STAT3 signaling and to effectively reduce MDSC populations (Ko et al., 2009; Cao et al., 2011). A similar effect can be achieved by using all-trans-retinoic acid (ATRA), an active metabolite of vitamin A (Almand et al., 2001; Mirza et al., 2006). Furthermore, the chemotherapeutic agents 5-Fluoruracil and gemcitabine have been shown to selectively eliminate MDSCs (Suzuki et al., 2005; Vincent et al., 2010). Conversely, in vivo expansion or adoptive transfer of MDSCs represents a promising strategy in $P$. aeruginosa infections or sepsis. 


\section{AUTHOR CONTRIBUTIONS}

MO searched databases and literature, wrote the manuscript, discussed data, composed the figure and created the table. AS contributed to manuscript writing. AP contributed to the S. aureus manuscript chapter writing and discussion part. RM contributed to manuscript writing. NR contributed to discussion of the literature and manuscript writing. $\mathrm{DH}$ co-wrote the manuscript, discussed findings and contributed to figure design.

\section{REFERENCES}

Akira, S., Uematsu, S., and Takeuchi, O. (2006). Pathogen recognition and innate immunity. Cell 124, 783-801. doi: 10.1016/j.cell.2006.02.015

Almand, B., Clark, J. I., Nikitina, E., van Beynen, J., English, N. R., Knight, S. C., et al. (2001). Increased production of immature myeloid cells in cancer patients: a mechanism of immunosuppression in cancer. J. Immunol. 166, 678-689. doi: 10.4049/jimmunol.166.1.678

Aranda, F., Vacchelli, E., Obrist, F., Eggermont, A., Galon, J., Sautes-Fridman, C., et al. (2014). Trial Watch: toll-like receptor agonists in oncological indications. Oncoimmunology 3:e29179. doi: 10.4161/onci.29179

Asea, A., Rehli, M., Kabingu, E., Boch, J. A., Bare, O., Auron, P. E., et al. (2002). Novel signal transduction pathway utilized by extracellular HSP70: role of toll-like receptor (TLR) 2 and TLR4. J. Biol. Chem. 277, 15028-15034. doi: 10.1074/jbc.M200497200

Bronte, V., Serafini, P., De Santo, C., Marigo, I., Tosello, V., Mazzoni, A., et al. (2003). IL-4-induced arginase 1 suppresses alloreactive T cells in tumor-bearing mice. J Immunol 170, 270-278. doi: 10.4049/jimmunol.170.1.270

Brudecki, L., Ferguson, D. A., McCall, C. E., and El Gazzar, M. (2012). Myeloidderived suppressor cells evolve during sepsis and can enhance or attenuate the systemic inflammatory response. Infect. Immun. 80, 2026-2034. doi: 10.1128/IAI.00239-12

Bunt, S. K., Clements, V. K., Hanson, E. M., Sinha, P., and Ostrand-Rosenberg, S. (2009). Inflammation enhances myeloid-derived suppressor cell cross-talk by signaling through Toll-like receptor 4. J. Leukoc. Biol. 85, 996-1004. doi: 10.1189/jlb.0708446

Cai, S., Batra, S., Shen, L., Wakamatsu, N., and Jeyaseelan, S. (2009). Both TRIF- and MyD88-dependent signaling contribute to host defense against pulmonary Klebsiella infection. J. Immunol. 183, 6629-6638. doi: 10.4049/jimmunol.0901033

Cai, W., Qin, A., Guo, P., Yan, D., Hu, F., Yang, Q., et al. (2013). Clinical significance and functional studies of myeloid-derived suppressor cells in chronic hepatitis C patients. J. Clin. Immunol. 33, 798-808. doi: 10.1007/s10875-012-9861-2

Cao, M., Xu, Y., Youn, J. I., Cabrera, R., Zhang, X., Gabrilovich, D., et al. (2011). Kinase inhibitor Sorafenib modulates immunosuppressive cell populations in a murine liver cancer model. Lab. Invest. 91, 598-608. doi: 10.1038/labinvest.2010.205

Chen, M. F., Kuan, F. C., Yen, T. C., Lu, M. S., Lin, P. Y., Chung, Y. H., et al. (2014). IL-6-stimulated CD11b+ CD14+ HLA-DR- myeloid-derived suppressor cells, are associated with progression and poor prognosis in squamous cell carcinoma of the esophagus. Oncotarget 5, 8716-8728. doi: 10.18632/oncotarget.2368

Cheng, P., Corzo, C. A., Luetteke, N., Yu, B., Nagaraj, S., Bui, M. M., et al. (2008). Inhibition of dendritic cell differentiation and accumulation of myeloidderived suppressor cells in cancer is regulated by S100A9 protein. J. Exp. Med. 205, 2235-2249. doi: 10.1084/jem.20080132

Cohen, T. S., and Prince, A. (2012). Cystic fibrosis: a mucosal immunodeficiency syndrome. Nat. Med. 18, 509-519. doi: 10.1038/nm.2715

Condamine, T., Kumar, V., Ramachandran, I. R., Youn, J. I., Celis, E., Finnberg, N., et al. (2014). ER stress regulates myeloid-derived suppressor cell fate through TRAIL-R-mediated apoptosis. J. Clin. Invest. 124, 2626-2639. doi: 10.1172/JCI74056

\section{FUNDING}

We thank the IZKF, University of Tübingen, the Deutsches Zentrum für Infektionsforschung (DZIF) and the DFG SFB/CRC685, University of Tübingen, for financial support.

\section{ACKNOWLEDGMENTS}

We thank Iris Schäfer and the whole "Rieber/Singh-lab," University of Tübingen, for their continuous support.

Condamine, T., Mastio, J., and Gabrilovich, D. I. (2015). Transcriptional regulation of myeloid-derived suppressor cells. J. Leukoc. Biol. 98, 913-922. doi: 10.1189/jlb.4RI0515-204R

Darcy, C. J., Minigo, G., Piera, K. A., Davis, J. S., McNeil, Y. R., Chen, Y., et al. (2014). Neutrophils with myeloid derived suppressor function deplete arginine and constrain T cell function in septic shock patients. Crit. Care 18:R163. doi: $10.1186 / \mathrm{cc} 14003$

Delano, M. J., Scumpia, P. O., Weinstein, J. S., Coco, D., Nagaraj, S., Kelly-Scumpia, K. M., et al. (2007). MyD88-dependent expansion of an immature GR$1(+) \mathrm{CD} 1 \mathrm{~b}(+)$ population induces $\mathrm{T}$ cell suppression and $\mathrm{Th} 2$ polarization in sepsis. J. Exp. Med. 204, 1463-1474. doi: 10.1084/jem.20062602

Derive, M., Bouazza, Y., Alauzet, C., and Gibot, S. (2012). Myeloid-derived suppressor cells control microbial sepsis. Intensive Care Med. 38, 1040-1049. doi: 10.1007/s00134-012-2574-4

Dietlin, T. A., Hofman, F. M., Lund, B. T., Gilmore, W., Stohlman, S. A., and van der Veen, R. C. (2007). Mycobacteria-induced Gr-1+ subsets from distinct myeloid lineages have opposite effects on T cell expansion. J. Leukoc Biol. 81, 1205-1212. doi: 10.1189/jlb.1006640

Dugast, A. S., Haudebourg, T., Coulon, F., Heslan, M., Haspot, F., Poirier, N., et al. (2008). Myeloid-derived suppressor cells accumulate in kidney allograft tolerance and specifically suppress effector T cell expansion. J. Immunol. 180, 7898-7906. doi: 10.4049/jimmunol.180.12.7898

du Plessis, N., Loebenberg, L., Kriel, M., von Groote-Bidlingmaier, F., Ribechini, E., Loxton, A. G., et al. (2013). Increased frequency of myeloid-derived suppressor cells during active tuberculosis and after recent mycobacterium tuberculosis infection suppresses T-cell function. Am. J. Respir. Crit. Care Med. 188, 724-732. doi: 10.1164/rccm.201302-0249OC

El Daker, S., Sacchi, A., Tempestilli, M., Carducci, C., Goletti, D., Vanini, V., et al. (2015). Granulocytic myeloid derived suppressor cells expansion during active pulmonary tuberculosis is associated with high nitric oxide plasma level. PLoS ONE 10:e0123772. doi: 10.1371/journal.pone.0123772

Ezernitchi, A. V., Vaknin, I., Cohen-Daniel, L., Levy, O., Manaster, E., Halabi, A., et al. (2006). TCR zeta down-regulation under chronic inflammation is mediated by myeloid suppressor cells differentially distributed between various lymphatic organs. J. Immunol. 177, 4763-1472. doi: 10.4049/jimmunol.177.7.4763

Fedtke, I., Gotz, F., and Peschel, A. (2004). Bacterial evasion of innate host defenses-the Staphylococcus aureus lesson. Int. J. Med. Microbiol. 294, 189-194. doi: 10.1016/j.ijmm.2004.06.016

Filipazzi, P., Valenti, R., Huber, V., Pilla, L., Canese, P., Iero, M., et al. (2007) Identification of a new subset of myeloid suppressor cells in peripheral blood of melanoma patients with modulation by a granulocyte-macrophage colonystimulation factor-based antitumor vaccine. J. Clin. Oncol. 25, 2546-2553. doi: 10.1200/JCO.2006.08.5829

Foell, D., Wittkowski, H., Vogl, T., and Roth, J. (2007). S100 proteins expressed in phagocytes: a novel group of damage-associated molecular pattern molecules. J. Leukoc Biol. 81, 28-37. doi: 10.1189/jlb.0306170

Foster, T. J. (2004). The Staphylococcus aureus "superbug". J. Clin. Invest. 114, 1693-1696. doi: 10.1172/JCI23825

Franchi, L., Stoolman, J., Kanneganti, T. D., Verma, A., Ramphal, R., and Nunez, G. (2007). Critical role for Ipaf in Pseudomonas aeruginosa-induced caspase-1 activation. Eur. J. Immunol. 37, 3030-3039. doi: 10.1002/eji.200737532 
Gabrilovich, D. I., Bronte, V., Chen, S. H., Colombo, M. P., Ochoa, A., Ostrand-Rosenberg, S., et al. (2007). The terminology issue for myeloidderived suppressor cells. Cancer Res 67, 425. doi: 10.1158/0008-5472.CAN06-3037

Gabrilovich, D. I., and Nagaraj, S. (2009). Myeloid-derived suppressor cells as regulators of the immune system. Nat. Rev. Immunol. 9, 162-174. doi: $10.1038 /$ nri2506

Gabrilovich, D. I., Ostrand-Rosenberg, S., and Bronte, V. (2012). Coordinated regulation of myeloid cells by tumours. Nat. Rev. Immunol. 12, 253-268. doi: $10.1038 /$ nri3175

Gabrilovich, D., Ishida, T., Oyama, T., Ran, S., Kravtsov, V., Nadaf, S., et al. (1998). Vascular endothelial growth factor inhibits the development of dendritic cells and dramatically affects the differentiation of multiple hematopoietic lineages in vivo. Blood 92, 4150-4166.

Gabrilovich, D. I., Velders, M. P., Sotomayor, E. M., and Kast, W. M. (2001). Mechanism of immune dysfunction in cancer mediated by immature Gr$1+$ myeloid cells. J. Immunol. 166, 5398-406. doi: 10.4049/jimmunol.166. 9.5398

Garban, H. J., and Bonavida, B. (2001). Nitric oxide inhibits the transcription repressor Yin-Yang 1 binding activity at the silencer region of the Fas promoter: a pivotal role for nitric oxide in the up-regulation of Fas gene expression in human tumor cells. J. Immunol. 167, 75-81. doi: 10.4049/jimmunol. 167.1.75

Garg, A., and Spector, S. A. (2014). HIV type 1 gp120-induced expansion of myeloid derived suppressor cells is dependent on interleukin 6 and suppresses immunity. J. Infect. Dis. 209, 441-451. doi: 10.1093/infdis/jit469

Goh, C. C., Roggerson, K. M., Lee, H. C., Golden-Mason, L., Rosen, H. R., and Hahn, Y. S. (2016). Hepatitis C virus-induced myeloid-derived suppressor cells suppress NK Cell IFN-gamma production by altering cellular metabolism via Arginase-1. J. Immunol. 196, 2283-2292. doi: 10.4049/jimmunol.1501881

Goh, C., Narayanan, S., and Hahn, Y. S. (2013). Myeloid-derived suppressor cells: the dark knight or the joker in viral infections? Immunol. Rev. 255, 210-221. doi: 10.1111/imr.12084

Haile, L. A., von Wasielewski, R., Gamrekelashvili, J., Kruger, C., Bachmann, O., Westendorf, A. M., et al. (2008). Myeloid-derived suppressor cells in inflammatory bowel disease: a new immunoregulatory pathway. Gastroenterology 135, 871-881, 81 e1-5. doi: 10.1053/j.gastro.2008.06.032

Hayashi, F., Smith, K. D., Ozinsky, A., Hawn, T. R., Yi, E. C., Goodlett, D. R., et al. (2001). The innate immune response to bacterial flagellin is mediated by Toll-like receptor 5. Nature 410, 1099-1103. doi: 10.1038/35074106

Heim, C. E., Vidlak, D., and Kielian, T. (2015a). Interleukin-10 production by myeloid-derived suppressor cells contributes to bacterial persistence during Staphylococcus aureus orthopedic biofilm infection. J. Leukoc. Biol. 98, 1003-1013. doi: 10.1189/jlb.4VMA0315-125RR

Heim, C. E., Vidlak, D., Scherr, T. D., Hartman, C. W., Garvin, K. L., and Kielian, T. (2015b). IL-12 promotes myeloid-derived suppressor cell recruitment and bacterial persistence during Staphylococcus aureus orthopedic implant infection. J. Immunol. 194, 3861-3872. doi: 10.4049/jimmunol.1402689

Heim, C. E., Vidlak, D., Scherr, T. D., Kozel, J. A., Holzapfel, M., Muirhead, D. E., et al. (2014). Myeloid-derived suppressor cells contribute to Staphylococcus aureus orthopedic biofilm infection. J. Immunol. 192, 3778-3792. doi: 10.4049/jimmunol.1303408

Hemmi, H., Takeuchi, O., Kawai, T., Kaisho, T., Sato, S., Sanjo, H., et al. (2000). A Toll-like receptor recognizes bacterial DNA. Nature 408, 740-745. doi: 10.1038/35047123

Hoechst, B., Ormandy, L. A., Ballmaier, M., Lehner, F., Kruger, C., Manns, M. P., et al. (2008). A new population of myeloid-derived suppressor cells in hepatocellular carcinoma patients induces CD4(+)CD25(+)Foxp3(+) T cells. Gastroenterology 135, 234-243. doi: 10.1053/j.gastro.2008.03.020

Hong, E. H., Chang, S. Y., Lee, B. R., Kim, Y. S., Lee, J. M., Kang, C. Y., et al. (2013). Blockade of Myd88 signaling induces antitumor effects by skewing the immunosuppressive function of myeloid-derived suppressor cells. Int. J. Cancer 132, 2839-2848. doi: 10.1002/ijc.27974

Hu, X., Li, B., Li, X., Zhao, X., Wan, L., Lin, G., et al. (2014). Transmembrane TNFalpha promotes suppressive activities of myeloid-derived suppressor cells via TNFR2. J. Immunol. 192, 1320-1331. doi: 10.4049/jimmunol.1203195

Janeway, C. A. Jr., and Medzhitov, R. (2002). Innate immune recognition. Annu. Rev. Immunol. 20, 197-216. doi: 10.1146/annurev.immunol.20.083001.084359
Janols, H., Bergenfelz, C., Allaoui, R., Larsson, A. M., Ryden, L., Bjornsson, S., et al (2014). A high frequency of MDSCs in sepsis patients, with the granulocytic subtype dominating in gram-positive cases. J. Leukoc. Biol. 96, 685-693. doi: 10.1189/jlb.5HI0214-074R

Jassal, M. S., and Bishai, W. R. (2010). Epidemiology and challenges to the elimination of global tuberculosis. Clin. Infect. Dis.50 (Suppl. 3), S156-S164. doi: $10.1086 / 651486$

Jones, R. N. (2010). Microbial etiologies of hospital-acquired bacterial pneumonia and ventilator-associated bacterial pneumonia. Clin. Infect. Dis. 51, S81-S87. doi: $10.1086 / 653053$

Kanno, K., Hirata, Y., Imai, T., Iwashina, M., and Marumo, F. (1994). Regulation of inducible nitric oxide synthase gene by interleukin-1 beta in rat vascular endothelial cells. Am. J. Physiol. 267(6 Pt 2), H2318-H2324.

Kawai, T., and Akira, S. (2010). The role of pattern-recognition receptors in innate immunity: update on Toll-like receptors. Nat. Immunol. 11, 373-384. doi: 10.1038/ni. 1863

Knaul, J. K., Jorg, S., Oberbeck-Mueller, D., Heinemann, E., Scheuermann, L., Brinkmann, V., et al. (2014). Lung-residing myeloid-derived suppressors display dual functionality in murine pulmonary tuberculosis. Am. J. Respir. Crit. Care Med. 190, 1053-1066. doi: 10.1164/rccm.201405-0828OC

Ko, J. S., Zea, A. H., Rini, B. I., Ireland, J. L., Elson, P., Cohen, P., et al. (2009). Sunitinib mediates reversal of myeloid-derived suppressor cell accumulation in renal cell carcinoma patients. Clin. Cancer Res. 15, 2148-2157. doi: 10.1158/1078-0432.CCR-08-1332

Kruger, P., Saffarzadeh, M., Weber, A. N., Rieber, N., Radsak, M., von Bernuth, H., et al. (2015). Neutrophils: Between host defence, immune modulation, and tissue injury. PLoS Pathog. 11:e1004651. doi: 10.1371/journal.ppat.1004651

Kwon, G., Corbett, J. A., Rodi, C. P., Sullivan, P., and McDaniel, M. L. (1995). Interleukin-1 beta-induced nitric oxide synthase expression by rat pancreatic beta-cells: evidence for the involvement of nuclear factor kappa B in the signaling mechanism. Endocrinology 136, 4790-4795. doi: 10.1210/endo.136.11.7588208

Levy, M. M., Fink, M. P., Marshall, J. C., Abraham, E., Angus, D., Cook, D., et al. (2003). 2001 SCCM/ESICM/ACCP/ATS/SIS International sepsis definitions conference. Intensive Care Med. 29, 530-538. doi: 10.1007/s00134-003-1662-x

Mandruzzato, S., Solito, S., Falisi, E., Francescato, S., Chiarion-Sileni, V., Mocellin, S., et al. (2009). IL4Ralpha+ myeloid-derived suppressor cell expansion in cancer patients. J. Immunol. 182, 6562-6568. doi: 10.4049/jimmunol.0803831

Martin, G. S., Mannino, D. M., Eaton, S., and Moss, M. (2003). The epidemiology of sepsis in the United States from 1979 through 2000. N. Engl. J. Med. 348, 1546-1554. doi: 10.1056/NEJMoa022139

Martino, A., Badell, E., Abadie, V., Balloy, V., Chignard, M., Mistou, M. Y., et al. (2010). Mycobacterium bovis bacillus Calmette-Guerin vaccination mobilizes innate myeloid-derived suppressor cells restraining in vivo $\mathrm{T}$ cell priming via IL-1R-dependent nitric oxide production. J. Immunol. 184, 2038-2047. doi: 10.4049/jimmunol.0903348

Maruyama, A., Shime, H., Takeda, Y., Azuma, M., Matsumoto, M., and Seya, T. (2015). Pam2 lipopeptides systemically increase myeloid-derived suppressor cells through TLR2 signaling. Biochem. Biophys. Res. Commun. 457, 445-450. doi: 10.1016/j.bbrc.2015.01.011

Mazzoni, A., Bronte, V., Visintin, A., Spitzer, J. H., Apolloni, E., Serafini, P., et al. (2002). Myeloid suppressor lines inhibit T cell responses by an NO-dependent mechanism. J. Immunol. 168, 689-695. doi: 10.4049/jimmunol.168.2.689

McClure, C., Brudecki, L., Ferguson, D. A., Yao, Z. Q., Moorman, J. P., McCall, C. E., et al. (2014). MicroRNA 21 (miR-21) and miR-181b couple with NFI-A to generate myeloid-derived suppressor cells and promote immunosuppression in late sepsis. Infect. Immun. 82, 3816-3825. doi: 10.1128/IAI.01495-14

Mirza, N., Fishman, M., Fricke, I., Dunn, M., Neuger, A. M., Frost, T. J., et al. (2006). All-trans-retinoic acid improves differentiation of myeloid cells and immune response in cancer patients. Cancer Res. 66, 9299-9307. doi: 10.1158/0008-5472.CAN-06-1690

Molon, B., Ugel, S., Del Pozzo, F., Soldani, C., Zilio, S., Avella, D., et al. (2011). Chemokine nitration prevents intratumoral infiltration of antigen-specific $\mathrm{T}$ cells. J. Exp. Med. 208, 1949-1962. doi: 10.1084/jem.20101956

Movahedi, K., Guilliams, M., Van den Bossche, J., Van den Bergh, R., Gysemans, C., Beschin, A., et al. (2008). Identification of discrete tumor-induced myeloidderived suppressor cell subpopulations with distinct T cell-suppressive activity. Blood 111, 4233-4244. doi: 10.1182/blood-2007-07-099226 
Munera, V., Popovic, P. J., Bryk, J., Pribis, J., Caba, D., Matta, B. M., et al. (2010). Stat 6-dependent induction of myeloid derived suppressor cells after physical injury regulates nitric oxide response to endotoxin. Ann. Surg. 251, 120-126. doi: 10.1097/SLA.0b013e3181bfda1c

Nagaraj, S., Gupta, K., Pisarev, V., Kinarsky, L., Sherman, S., Kang, L., et al. (2007). Altered recognition of antigen is a mechanism of CD8 $+\mathrm{T}$ cell tolerance in cancer. Nat Med 13, 828-835. doi: 10.1038/nm1609

Nagaraj, S., Nelson, A., Youn, J. I., Cheng, P., Quiceno, D., and Gabrilovich, D. I. (2012). Antigen-specific CD4(+) T cells regulate function of myeloid-derived suppressor cells in cancer via retrograde MHC class II signaling. Cancer Res. 72, 928-938. doi: 10.1158/0008-5472.CAN-11-2863

Nagaraj, S., Schrum, A. G., Cho, H. I., Celis, E., and Gabrilovich, D. I. (2010a). Mechanism of T cell tolerance induced by myeloid-derived suppressor cells. J. Immunol. 184, 3106-3116. doi: 10.4049/jimmunol.0902661

Nagaraj, S., Youn, J. I., and Gabrilovich, D. I. (2013). Reciprocal relationship between myeloid-derived suppressor cells and T cells. J. Immunol. 191, 17-23. doi: 10.4049/jimmunol.1300654

Nagaraj, S., Youn, J. I., Weber, H., Iclozan, C., Lu, L., Cotter, M. J., et al. (2010b). Anti-inflammatory triterpenoid blocks immune suppressive function of MDSCs and improves immune response in cancer. Clin. Cancer Res. 16, 1812-1823. doi: 10.1158/1078-0432.CCR-09-3272

Nguyen, M. T., Kraft, B., Yu, W., Demicrioglu, D. D., Hertlein, T., Burian, M., et al. (2015). The nuSaalpha Specific Lipoprotein Like Cluster (lpl) of S. aureus USA300 Contributes to Immune Stimulation and Invasion in Human Cells. PLoS Pathog 11:e1004984. doi: 10.1371/journal.ppat.1004984

Norris, B. A., Uebelhoer, L. S., Nakaya, H. I., Price, A. A., Grakoui, A., and Pulendran, B. (2013). Chronic but not acute virus infection induces sustained expansion of myeloid suppressor cell numbers that inhibit viralspecific T cell immunity. Immunity 38, 309-321. doi: 10.1016/j.immuni.2012. 10.022

Obregon-Henao, A., Henao-Tamayo, M., Orme, I. M., and Ordway, D. J. (2013). Gr1(int)CD11b+ myeloid-derived suppressor cells in Mycobacterium tuberculosis infection. PLoS ONE 8:e80669. doi: 10.1371/journal.pone.0080669

Ochoa, A. C., Zea, A. H., Hernandez, C., and Rodriguez, P. C. (2007). Arginase, prostaglandins, and myeloid-derived suppressor cells in renal cell carcinoma. Clin Cancer Res 13(2 Pt 2):721s-726s. doi: 10.1158/1078-0432.CCR-06-2197

Ostrand-Rosenberg, S., Sinha, P., Beury, D. W., and Clements, V. K. (2012). Crosstalk between myeloid-derived suppressor cells (MDSC), macrophages, and dendritic cells enhances tumor-induced immune suppression. Semin. Cancer Biol. 22, 275-281. doi: 10.1016/j.semcancer.2012.01.011

Ozinsky, A., Underhill, D. M., Fontenot, J. D., Hajjar, A. M., Smith, K. D., Wilson, C. B., et al. (2000). The repertoire for pattern recognition of pathogens by the innate immune system is defined by cooperation between toll-like receptors. Proc. Natl. Acad. Sci. U.S.A. 97, 13766-13771. doi: 10.1073/pnas.250476497

Poe, S. L., Arora, M., Oriss, T. B., Yarlagadda, M., Isse, K., Khare, A., et al. (2013). STAT1-regulated lung MDSC-like cells produce IL-10 and efferocytose apoptotic neutrophils with relevance in resolution of bacterial pneumonia. Mucosal Immunol. 6, 189-199. doi: 10.1038/mi.2012.62

Poltorak, A., He, X., Smirnova, I., Liu, M. Y., Van Huffel, C., Du, X., et al. (1998). Defective LPS signaling in $\mathrm{C} 3 \mathrm{H} / \mathrm{HeJ}$ and $\mathrm{C} 57 \mathrm{BL} / 10 \mathrm{ScCr}$ mice: mutations in Tlr4 gene. Science 282, 2085-2088.

Qin, A., Cai, W., Pan, T., Wu, K., Yang, Q., Wang, N., et al. (2013). Expansion of monocytic myeloid-derived suppressor cells dampens $\mathrm{T}$ cell function in HIV1-seropositive individuals. J. Virol. 87, 1477-1490. doi: 10.1128/JVI.01759-12

Qin, C. L., Huang, W., Zhou, S. Q., Wang, X. C., Liu, H. H., Fan, M. H., et al. (2014). Characterization of a novel antimicrobial peptide with chitin-biding domain from Mytilus coruscus. Fish Shellfish Immunol. 41, 362-370. doi: 10.1016/j.fsi.2014.09.019

Rieber, N., Brand, A., Hector, A., Graepler-Mainka, U., Ost, M., Schäfer, I., et al. (2013). Flagellin induces myeloid-derived suppressor cells: implications for Pseudomonas aeruginosa Infection in Cystic Fibrosis Disease. J. Immunol. 190, 1276-1284. doi: 10.4049/jimmunol.1202144

Rieber, N., Singh, A., Oz, H., Carevic, M., Bouzani, M., Amich, J., et al. (2015). Pathogenic fungi regulate immunity by inducing neutrophilic myeloid-derived suppressor cells. Cell Host Microbe 17, 507-514. doi: 10.1016/j.chom.2015.02.007

Roth, F., De La Fuente, A. C., Vella, J. L., Zoso, A., Inverardi, L., and Serafini, P. (2012). Aptamer-mediated blockade of IL4Ralpha triggers apoptosis of MDSCs and limits tumor progression. Cancer Res 72, 1373-1383. doi: 10.1158/00085472.CAN-11-2772

Rutschman, R., Lang, R., Hesse, M., Ihle, J. N., Wynn, T. A., and Murray, P. J. (2001). Cutting edge: Stat6-dependent substrate depletion regulates nitric oxide production. J. Immunol. 166, 2173-2177. doi: 10.4049/jimmunol.166. 4.2173

Sade-Feldman, M., Kanterman, J., Ish-Shalom, E., Elnekave, M., Horwitz, E., and Baniyash, M. (2013). Tumor necrosis factor-alpha blocks differentiation and enhances suppressive activity of immature myeloid cells during chronic inflammation. Immunity 38, 541-554. doi: 10.1016/j.immuni.2013.02.007

Saeed, K., Marsh, P., and Ahmad, N. (2014). Cryptic resistance in Staphylococcus aureus: a risk for the treatment of skin infection? Curr. Opin. Infect. Dis. 27, 130-136. doi: 10.1097/QCO.0000000000000046

Sander, L. E., Sackett, S. D., Dierssen, U., Beraza, N., Linke, R. P., Muller, M., et al. (2010). Hepatic acute-phase proteins control innate immune responses during infection by promoting myeloid-derived suppressor cell function. J. Exp. Med. 207, 1453-1464. doi: 10.1084/jem.20091474

Sawanobori, Y., Ueha, S., Kurachi, M., Shimaoka, T., Talmadge, J. E., Abe, J., et al. (2008). Chemokine-mediated rapid turnover of myeloid-derived suppressor cells in tumor-bearing mice. Blood 111, 5457-5466. doi: 10.1182/blood-200801-136895

Schreiner, J., Kretschmer, D., Klenk, J., Otto, M., Buhring, H. J., Stevanovic, S., et al. (2013). Staphylococcus aureus phenol-soluble modulin peptides modulate dendritic cell functions and increase in vitro priming of regulatory T cells. J. Immunol. 190, 3417-3426. doi: 10.4049/jimmunol.1202563

Serafini, P. (2013). Myeloid derived suppressor cells in physiological and pathological conditions: the good, the bad, and the ugly. Immunol. Res. 57, 172-184. doi: 10.1007/s12026-013-8455-2

Serafini, P., Carbley, R., Noonan, K. A., Tan, G., Bronte, V., and Borrello, I. (2004). High-dose granulocyte-macrophage colony-stimulating factorproducing vaccines impair the immune response through the recruitment of myeloid suppressor cells. Cancer Res. 64, 6337-6343. doi: 10.1158/00085472.CAN-04-0757

Serafini, P., Mgebroff, S., Noonan, K., and Borrello, I. (2008). Myeloid-derived suppressor cells promote cross-tolerance in B-cell lymphoma by expanding regulatory T cells. Cancer Res. 68, 5439-5449. doi: 10.1158/0008-5472.CAN07-6621

Shirota, Y., Shirota, H., and Klinman, D. M. (2012). Intratumoral injection of CpG oligonucleotides induces the differentiation and reduces the immunosuppressive activity of myeloid-derived suppressor cells. J. Immunol. 188, 1592-1599. doi: 10.4049/jimmunol.1101304

Sinha, P., Chornoguz, O., Clements, V. K., Artemenko, K. A., Zubarev, R. A., and Ostrand-Rosenberg, S. (2011). Myeloid-derived suppressor cells express the death receptor Fas and apoptose in response to T cell-expressed FasL. Blood 117, 5381-5390. doi: 10.1182/blood-2010-11-321752

Sinha, P., Clements, V. K., Bunt, S. K., Albelda, S. M., and Ostrand-Rosenberg, S. (2007). Cross-talk between myeloid-derived suppressor cells and macrophages subverts tumor immunity toward a type 2 response. J. Immunol. 179, 977-983. doi: 10.4049/jimmunol.179.2.977

Sinha, P., Okoro, C., Foell, D., Freeze, H. H., Ostrand-Rosenberg, S., and Srikrishna, G. (2008). Proinflammatory S100 proteins regulate the accumulation of myeloid-derived suppressor cells. J. Immunol. 181, 4666-4675. doi: 10.4049/jimmunol.181.7.4666

Skabytska, Y., Wolbing, F., Gunther, C., Koberle, M., Kaesler, S., Chen, K. M., et al. (2014). Cutaneous innate immune sensing of Toll-like receptor 2-6 ligands suppresses $\mathrm{T}$ cell immunity by inducing myeloid-derived suppressor cells. Immunity 41, 762-775. doi: 10.1016/j.immuni.2014.10.009

Smith, T., Pearson, M., Wilcox, K., Cruz, C., Lancaster, M., Robinson-Dunn, B., et al. (1999). Emergence of vancomycin resistance in Staphylococcus aureus. N. Engl. J. Med. 340, 493-501.

Song, X., Krelin, Y., Dvorkin, T., Bjorkdahl, O., Segal, S., Dinarello, C. A., et al. (2005). CD11b+/Gr-1+ immature myeloid cells mediate suppression of T cells in mice bearing tumors of IL-1beta-secreting cells. J. Immunol. 175, 8200-8208. doi: 10.4049/jimmunol.175.12.8200

Srivastava, M. K., Sinha, P., Clements, V. K., Rodriguez, P., and OstrandRosenberg, S. (2010). Myeloid-derived suppressor cells inhibit T-cell activation by depleting cystine and cysteine. Cancer Res 70, 68-77. doi: 10.1158/00085472.CAN-09-2587 
Suzuki, E., Kapoor, V., Jassar, A. S., Kaiser, L. R., and Albelda, S. M. (2005). Gemcitabine selectively eliminates splenic Gr-1+/CD11b + myeloid suppressor cells in tumor-bearing animals and enhances antitumor immune activity. Clin. Cancer Res. 11, 6713-6721. doi: 10.1158/1078-0432.CCR-05-0883

Tacke, R. S., Lee, H. C., Goh, C., Courtney, J., Polyak, S. J., Rosen, H. R., et al. (2012). Myeloid suppressor cells induced by hepatitis $\mathrm{C}$ virus suppress $\mathrm{T}$-cell responses through the production of reactive oxygen species. Hepatology 55, 343-353. doi: 10.1002/hep. 24700

Tebartz, C., Horst, S. A., Sparwasser, T., Huehn, J., Beineke, A., Peters, G., et al. (2015). A major role for myeloid-derived suppressor cells and a minor role for regulatory $\mathrm{T}$ cells in immunosuppression during Staphylococcus aureus infection. J. Immunol. 194, 1100-1111. doi: 10.4049/jimmunol.1400196

Thurlow, L. R., Hanke, M. L., Fritz, T., Angle, A., Aldrich, A., Williams, S. H., et al. (2011). Staphylococcus aureus biofilms prevent macrophage phagocytosis and attenuate inflammation in vivo. J. Immunol. 186, 6585-6596. doi: 10.4049/jimmunol.1002794

Tsiganov, E. N., Verbina, E. M., Radaeva, T. V., Sosunov, V. V., Kosmiadi, G. A., Nikitina, I. Y., et al. (2014). Gr-1dimCD11b+ immature myeloid-derived suppressor cells but not neutrophils are markers of lethal tuberculosis infection in mice. J. Immunol. 192, 4718-4727. doi: 10.4049/jimmunol.1301365

Tu, S., Bhagat, G., Cui, G., Takaishi, S., Kurt-Jones, E. A., Rickman, B., et al. (2008). Overexpression of interleukin-1beta induces gastric inflammation and cancer and mobilizes myeloid-derived suppressor cells in mice. Cancer Cell 14, 408-419. doi: 10.1016/j.ccr.2008.10.011

Tumino, N., Turchi, F., Meschi, S., Lalle, E., Bordoni, V., Casetti, R., et al. (2015). In HIV-positive patients, myeloid-derived suppressor cells induce Tcell anergy by suppressing CD3zeta expression through ELF-1 inhibition. AIDS 29, 2397-2407. doi: 10.1097/QAD.0000000000000871

Van Ginderachter, J. A., Beschin, A., De Baetselier, P., and Raes, G. (2010). Myeloid-derived suppressor cells in parasitic infections. Eur. J. Immunol. 40, 2976-2985. doi: 10.1002/eji.201040911

Vincent, J., Mignot, G., Chalmin, F., Ladoire, S., Bruchard, M., Chevriaux, A., et al. (2010). 5-Fluorouracil selectively kills tumor-associated myeloid-derived suppressor cells resulting in enhanced T cell-dependent antitumor immunity. Cancer Res 70, 3052-3061. doi: 10.1158/0008-5472.CAN-09-3690

Waldron, T. J., Quatromoni, J. G., Karakasheva, T. A., Singhal, S., and Rustgi, A. K. (2013). Myeloid derived suppressor cells: targets for therapy. Oncoimmunology 2:e24117. doi: 10.4161/onci.24117

Watanabe, S., Deguchi, K., Zheng, R., Tamai, H., Wang, L. X., Cohen, P. A., et al. (2008). Tumor-induced CD11b+Gr-1+ myeloid cells suppress T cell sensitization in tumor-draining lymph nodes. J. Immunol. 181, 3291-3300. doi: 10.4049/jimmunol.181.5.3291

Weidenmaier, C., Goerke, C., and Wolz, C. (2012). Staphylococcus aureus determinants for nasal colonization. Trends Microbiol. 20, 243-250. doi: 10.1016/j.tim.2012.03.004

Weinstein, M. P., Towns, M. L., Quartey, S. M., Mirrett, S., Reimer, L. G., Parmigiani, G., et al. (1997). The clinical significance of positive blood cultures in the 1990s: a prospective comprehensive evaluation of the microbiology, epidemiology, and outcome of bacteremia and fungemia in adults. Clin. Infect. Dis. 24, 584-602.

Wieland, C. W., van Lieshout, M. H., Hoogendijk, A. J., and van der Poll, T. (2011). Host defence during Klebsiella pneumonia relies on haematopoieticexpressed Toll-like receptors 4 and 2. Eur. Respir. J. 37, 848-857. doi: 10.1183/09031936.00076510

Wu, C. T., Hsieh, C. C., Lin, C. C., Chen, W. C., Hong, J. H., and Chen, M. F. (2012). Significance of IL-6 in the transition of hormone-resistant prostate cancer and the induction of myeloid-derived suppressor cells. J. Mol. Med. (Berl.) 90, 1343-1355. doi: 10.1007/s00109-012-0916-x

Wu, G., and Morris, S. M. Jr. (1998). Arginine metabolism: nitric oxide and beyond. Biochem. J. 336 (Pt 1), 1-17.

Wyllie, D. H., Kiss-Toth, E., Visintin, A., Smith, S. C., Boussouf, S., Segal, D. M., et al. (2000). Evidence for an accessory protein function for Tolllike receptor 1 in anti-bacterial responses. J. Immunol. 165, 7125-7132. doi: 10.4049/jimmunol.165.12.7125

Xin, H., Zhang, C., Herrmann, A., Du, Y., Figlin, R., and Yu, H. (2009). Sunitinib inhibition of Stat 3 induces renal cell carcinoma tumor cell apoptosis and reduces immunosuppressive cells. Cancer Res. 69, 2506-2513. doi: 10.1158/0008-5472.CAN-08-4323
Yang, B., Wang, X., Jiang, J., Zhai, F., and Cheng, X. (2014). Identification of CD244-expressing myeloid-derived suppressor cells in patients with active tuberculosis. Immunol. Lett. 158, 66-72. doi: 10.1016/j.imlet.2013.12.003

Yi, H., Guo, C., Yu, X., Zuo, D., and Wang, X. Y. (2012). Mouse CD11b+Gr-1+ myeloid cells can promote Th17 cell differentiation and experimental autoimmune encephalomyelitis. J. Immunol. 189, 4295-4304. doi: 10.4049/jimmunol.1200086

Youn, J. I., Kumar, V., Collazo, M., Nefedova, Y., Condamine, T., Cheng, P., et al. (2013). Epigenetic silencing of retinoblastoma gene regulates pathologic differentiation of myeloid cells in cancer. Nat. Immunol. 14, 211-220. doi: $10.1038 /$ ni.2526

Youn, J. I., Nagaraj, S., Collazo, M., and Gabrilovich, D. I. (2008). Subsets of myeloid-derived suppressor cells in tumor-bearing mice. J. Immunol. 181, 5791-5802. doi: 10.4049/jimmunol.181.8.5791

Young, M. R., Newby, M., and Wepsic, H. T. (1987). Hematopoiesis and suppressor bone marrow cells in mice bearing large metastatic Lewis lung carcinoma tumors. Cancer Res. 47, 100-105.

Yu, H., Pardoll, D., and Jove, R. (2009). STATs in cancer inflammation and immunity: a leading role for STAT3. Nat. Rev. Cancer 9, 798-809. doi: $10.1038 / \mathrm{nrc} 2734$

Zea, A. H., Rodriguez, P. C., Atkins, M. B., Hernandez, C., Signoretti, S., Zabaleta, J., et al. (2005). Arginase-producing myeloid suppressor cells in renal cell carcinoma patients: a mechanism of tumor evasion. Cancer Res. 65, 3044-3048. doi: 10.1158/0008-5472.CAN-04-4505

Zea, A. H., Rodriguez, P. C., Culotta, K. S., Hernandez, C. P., DeSalvo, J., Ochoa, J. B., et al. (2004). L-Arginine modulates CD3zeta expression and T cell function in activated human T lymphocytes. Cell. Immunol. 232, 21-31. doi: 10.1016/j.cellimm.2005.01.004

Zhan, X., Fang, Y., Hu, S., Wu, Y., Yang, K., Liao, C., et al. (2015). IFN-gamma differentially regulates subsets of $\mathrm{Gr}-1(+) \mathrm{CD} 11 \mathrm{~b}(+)$ myeloid cells in chronic inflammation. Mol. Immunol. 66, 451-462. doi: 10.1016/j.molimm.2015.05.011

Zhang, H., Wang, S., Huang, Y., Wang, H., Zhao, J., Gaskin, F., et al. (2015). Myeloid-derived suppressor cells are proinflammatory and regulate collagen-induced arthritis through manipulating Th17 cell differentiation. Clin. Immunol. 157, 175-186. doi: 10.1016/j.clim.2015.02.001

Zhang, Y. L., Luan, B., Wang, X. F., Qiao, J. Y., Song, L., Lei, R. R., et al. (2013). Peripheral blood MDSCs, IL-10 and IL-12 in children with asthma and their importance in asthma development. PLoS ONE 8:e63775. doi: 10.1371/journal.pone.0063775

Zhang, Z., Louboutin, J. P., Weiner, D. J., Goldberg, J. B., and Wilson, J. M. (2005) Human airway epithelial cells sense Pseudomonas aeruginosa infection via recognition of flagellin by Toll-like receptor 5. Infect. Immun. 73, 7151-7160. doi: 10.1128/IAI.73.11.7151-7160.2005

Zhao, B. G., Vasilakos, J. P., Tross, D., Smirnov, D., and Klinman, D. M. (2014). Combination therapy targeting toll like receptors 7,8 and 9 eliminates large established tumors. J. Immunother. Cancer 2:12. doi: 10.1186/2051-1426-2-12

Zhao, X., Rong, L., Zhao, X., Li, X., Liu, X., Deng, J., et al. (2012). TNF signaling drives myeloid-derived suppressor cell accumulation. J. Clin. Invest. 122, 4094-4104. doi: 10.1172/JCI64115

Zhuang, Y., Cheng, P., Liu, X. F., Peng, L. S., Li, B. S., Wang, T. T., et al. (2015). A pro-inflammatory role for Th22 cells in Helicobacter pylori-associated gastritis. Gut 64, 1368-1378. doi: 10.1136/gutjnl-2014-307020

Zoglmeier, C., Bauer, H., Norenberg, D., Wedekind, G., Bittner, P., Sandholzer, N., et al. (2011). CpG blocks immunosuppression by myeloid-derived suppressor cells in tumor-bearing mice. Clin. Cancer Res. 17, 1765-1775. doi: 10.1158/1078-0432.CCR-10-2672

Conflict of Interest Statement: The authors declare that the research was conducted in the absence of any commercial or financial relationships that could be construed as a potential conflict of interest.

Copyright (C) 2016 Ost, Singh, Peschel, Mehling, Rieber and Hartl. This is an openaccess article distributed under the terms of the Creative Commons Attribution License (CC BY). The use, distribution or reproduction in other forums is permitted, provided the original author(s) or licensor are credited and that the original publication in this journal is cited, in accordance with accepted academic practice. No use, distribution or reproduction is permitted which does not comply with these terms. 